\title{
CARTESIANISMO, FENOMENOLOGÍA Y SOLIPSISMO
}

\author{
Manuel Cabrera
}

INSTTTUTO DE INVESTIGAciones FLLOSÓFICAS Universidad Nacional autónoma de México

1. En el tratamiento de los temas comunes, el cartesianismo y la fenomenología coinciden y divergen, porque la fenomenología pretende desarrollar radicalmente los temas cartesianos, para descubrir en ellos su sentido trascendental. ${ }^{1}$

Coinciden Descartes y Husserl en el intento de reformar el saber para hacerlo absoluto; pero divergen, pues Descartes conserva el ideal de la ciencia matemática mientras que Husserl considera que este ideal ha tenido una influencia nefasta. La duda metódica cartesiana y la reducción husserliana llegan a un mismo resultado, el descubrimiento del ego trascendental, pero Descartes, según Husserl, psicologiza la subjetividad que descubre. $Y$, en cuanto a la cuestión de superar el escollo solipsista que confrontan los dos grandes filósofos, Descartes trata de solucionarlo apoyándose en la veracidad divina, mientras que Husserl lo intenta recurriendo únicamente a la veracidad de la conciencia. De esto último se siguen posiciones contrapuestas en relación con el problema de Dios.

2. La fenomenología quiere ser un neocartesianismo, hacer patente el sentido escondido del cartesianismo, eliminando el objetivismo que en Descartes se mezcla con el motivo trascendental: "El estudio de las meditaciones ha influido muy directamente en la transformación de la fenomenología, que ya germinaba, en una variedad nueva de la filosofía trascendental. Casi se podria llamar a la fenomenología un nuevo cartesianismo, a pesar de lo muy obligada que está a rechazar casi todo el conocido contenido doctrinal de la filosofía cartesiana, justamente por desarrollar motivos cartesianos de una manera radical." 2

Husserl, como Descartes, busca una nueva fundación del conocimien-

1 Véase M. Cabrera, Bases para una fundamentación de la Sociologia, 1938 y 1953; Los supuestos del idealismo fenomenológico, 1979; F. Romero, Descartes y Husserl, La Plata, 1938; A. Gurvitsch, James Street Fulton's, The Cartesianism of Phenomenology, Philosophical and Phenomenological Research, June 1942.

2 E. Husserl, Meditaciones cartesianas, El Colegio de México, 1942, p. 3. 
to, ".. .una reforma completa de la filosofía que haga de ésta una cien. cia de una fundamentación absoluta. Esto incluye para Descartes una reforma homóloga de todas las ciencias. En efecto, éstas son, según él, simples miembros subordinados de la ciencia universal y única que es la filosofía".

El conocimiento filosófico debe hacer abstracción de todo prejuicio y volver a empezar de una manera radical apoyándose en evidencias indiscutibles, Husserl y Descartes se proponen el mismo fin, llegar al conocimiento ábsoluto, pero su idea de este conocimiento no será la misma. Para el filósofo francés el conocimiento es inseguro e incluso llega a suponer la existencia de un "genio maligno" que lo engaña, pero lo que se propone es dar un nuevo valor a la ciencia matemática y construir la metafísica a su imagen y semejanza. Husserl, al contrario, considera que "Descartes tenía por adelantado un ideal de ciencia, el de la geometría, o, si se quiere, el de la ciencia matemática. Este ideal decide como un prejuicio fatal de aquellos siglos, y decide también sin ser sometido a crítica de las Meditaciones mismas". ${ }^{4}$ Para Husserl el conocimiento radical no será el de las matemáticas sino solamente el saber fundado en la subjetividad trascendental. La construcción radical del conocimiento deberá hacerse a partir de la evidencia de la conciencia.

3. La duda cartesiana y la reducción fenomenológica son similares. Una y otra conducen al ego trascendental. Pero Descartes, que descubre el motivo trascendental, no llegará a comprender, piensa Husserl, la significación verdadera de su gran descubrimiento y llegará, inclusive, a falsificar el ego trascendental atribuyéndole predicados psicológicos. Descartes tendrá una noción psicológica de la inmanencia. Además, Husserl insiste en la diferencia entre su método y el método cartesiano: "En lugar del intento cartesiano de llevar a cabo una duda universal, podríamos colocar la epojé universal, en nuestro nuevo sentido rigurosamente determinado." 5 La epojé, a diferencia de la duda universal, se limita a poner entre paréntesis la tesis de que se trata: "No abandonamos la tesis que hemos practicado, no hacemos cambiar en nada nuestra convicción, que sigue siendo lo que es mientras no introducimos nuevas razones de juzgar, que es justamente lo que no hacemos.Y, sin embargo, experimenta la tesis una modificación mientras sigue siendo lo que es, la ponemos, por decirlo así, 'fuera de juego', la 'desconectamos', 'la colocamos entre paréntesis'." " La colocación entre paréntesis da como resultado no la nada, sino la certidumbre trascendental del

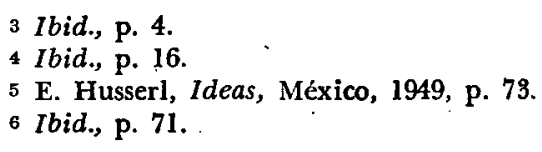


sujeto. La reducción fenomenológica suspende la actitud natural en lo que concierne a su pretensión de existencia, pretensión que no es negada, sino simplemente neutralizada, suspendida. Las tesis naturales ponen el mundo como existente, la actitud fenomenológica se desinteresa de la pretensión existencial para analizar solamente las tesis mismas. En Descartes, dice Husserl, la duda se encuentra ligada a la existencia y tiende a una negación universal; la reducción fenomenológica se limita a suspender para indagar el sentido.

4. El deseo de fundar el conocimiento de una manera radical implica el principio de exención de supuestos, pues el saber deberá construirse sobre evidencias absolutas. Aunque Descartes pretende hacer abstracción de todo supuesto conserva el ideal de la ciencia matemática. Husserl, más radical que Descartes, no aceptará este ideal y se atendrá al "principio de los principios", es decir, el "principio de la intuición", y, desde luego, a la intuición del ego trascendental.?

5. Descartes descubre la subjetividad trascendental: es el gran descubrimiento cartesiano que resiste a la duda y constituye la esfera del ser abolutamente evidente. El ego trascendental es el fundador de toda realidad. Descartes descubre el motivo trascendental e incluso maneja la intencionalidad de la conciencia, ya que hace participar a los cogitata de la apodicticidad del ego. Pero, la intencionalidad como esencia de la vida egológica no es desarrollada por el gran filósofo del siglo xviI, quien no logra comprenderse a sí mismo y falsifica psicológicamente el ego trascendental descubierto por la duda. Ello se debe a que no sostiene hasta el fin el radicalismo original de sus pensamientos. El gran error cartesiano consiste en comprender el ego como residuo del mundo, o, lo que es lo mismo, en identificar la subjetividad con el alma. De esta suerte el gran descubrimiento de la subjetividad trascendental pierde su valor; no llega a liberarse de "mundanidad". En realidad el mundo se explica por el ego, este es su principio, su fundamento, su razón de ser.

Descartes, al confundir la inmanencia psicológica con la egológica, se plantea el falso problema del valor metafísicamente trascendente de los productos de la razón; no vio que todo sentido sólo es posible en el ego absoluto, fundador de la trascendencia. ${ }^{8}$

7 No siempre sostuvo Husserl la misma posición con relación al ego. En las Investigaciones lógicas afirmó una concepción noegológica de la conciencia: "El ego fenomenológicamente reducido, no es, por consiguiente, nada de particular que flota sobre las múltiples vivencias: es simplemente idéntico a la unidad sintética propia de ellas." En las Ideas vuelve Husserl a la concepción clásica de la conciencia egológica, y, finalmente, en las Meditaciones sostiene la tesis de un ego concreto, sustrato de sus habitualidades.

8 E. Husserl, Die Krisis der europäischen Wissenscaften... etcétera, Den Haag, 1954, n? 17. 
La subjetividad es para Husserl "... .la esfera del ser que precede por principio y como presupuesto apodíctico, toda existencia concebible". 9 Así pues, en la subjetividad trascendental Husserl encuentra el fundamento de la metafísica, el principio a partir del cual podrá dar cuenta del universo. Esto se encuentra también en Descartes, pero solamente de una manera implícita, sin haber sido desarrollado y cubierto por "el contenido doctrinal conocido del cartesianismo". Husserl toma de Descartes el motivo radical de una conciencia trascendental, que desarrolla hasta la construcción del neocartesianismo egológico, que se distingue del cartesianismo explícito o manifiesto. Descartes inaugura ciertamente un nuevo tipo de filosofía, pero su descubrimiento esencial naufraga en las sedimentaciones culturales de las que no es capaz de deshacerse. Es decir, confunde la inmanencia psicológica con la egológica; ${ }^{10}$ incurre en falsas interpretaciones por inclinarse ante las sedimentaciones objetivistas. En suma, Descartes decubre el ego pero no construye la egología.

6. Tanto en el cartesianismo como en la fenomenologia llega un momento en que aparece el "fantasma del solipsismo"."1 Dice muy bien Robinson: "Reconociendo la existencia de un yo concreto y único y no un yo abstracto y universal del que los yo individuales no serían sino modificaciones o participaciones, llega Descartes, momentáneamente, a una forma de idealismo que no es otra cosa sino solipsismo." 12 Para

9 Ibid., $\mathrm{n}^{\circ} 19$.

10 "Bajo la forma fatal de la sustitución al ego, del yo psicológico propio; a la inmanencia egológica, de la inmanencia psicológica; a la percepción de sí egológica, de la evidencia de la 'percepción de sí' o 'percepción interior' al sentido psicológico. Bajo esta forma las Meditaciones de Descartes han desarrollado su acción históricamente hasta nuestros días." E. Husserl, Krisis, no 19, p. 83.

11 "Para infantes en filosofía este puede ser el oscuro paraje en que merodean los fantasmas del solipsismo, o aun, del psicologismo, del relativismo. El verdadero filósofo preferirá, en lugar de huir ante ellos, iluminar ese oscuro paraje." E. Husserl, Lógica Formal y' Lógica Trascendental, México, 1962, p. 248. El paraje en que merodea el fantasma del solipsismo es la conciencia trascendental que de pronto se oscurece. Para Husserl la salvación consiste en iluminar el "oscuro paraje" pero sin abandonarlo: ahondando en la inmanencia, "saliendo hacia adentro". Para Descartes la luz está más allá del paraje; sólo se puede salir de él hacia fuera. En Husserl, al filo de la contradicción, la trascendencia inmanente que "sale hacia adentro" será el correlato necesario de la intencionalidad que "entra hacia afuera". El carácter solipsista del cogito husserliano es patente: "Como absolutamente indudable, como innegable, aun cuando este mundo no existiese, el meditador se encuentra solamente consigo mismo, en cuanto puro ego de sus cogitaciones. El ego, así reducido, lleva a cabo, pues, una especie de filosofar solipsista... En suma, no sólo la naturaleza corporal, sino el total y concreto mundo circundante de la vida es, desde luego, para mí, mero fenómeno, mera apariencia de realidad, en lugar de realidad". E. Husserl, Medit., pp. 6 y 34. En lo que hace a Descartes, es evidente el estilo solipsista de su idealismo.

12 L. Robinson, "Le 'cogito' cartésien", Revue Philosophique, mai-août, 1937, París, p. 308. 
Descartes el problema del solipsismo será fundamental. Una vez que ha hecho abstracción de la certeza del mundo y afirmado la evidencia de la conciencia tendrá que intentar superar la reclusión inmanentista. El problema del solipsismo no es para Descartes el problema de las otras subjetividades; no tendrá que inventar una teoría para demostrar la existencia del otro y afirmar el mundo intersubjetivo. El problema se confunde en el cartesianismo con el problema de Dios y para resolverlo Descartes vuelve a descubrir el argumento ontológico, con el que demuestra, intuyéndola, la existencia de Dios: la existencia pertenece a la esencia de Dios, pues así como "no se puede concebir un triángulo sin tres ángulos o una montaña sin valle", no se puede concebir a Dios sin la existencia. ${ }^{13}$

Resuelto el problema de Dios podrá Descartes, apoyándose en la veracidad divina, afirmar la realidad intersubjetiva del mundo y la verdad del conocimiento: Deus, qui summe perfectum et verax est. Así pasa Descartes de la inmanencia de la conciencia a la trascendencia del mundo, por el camino de la veracidad divina. La noción de Dios es, pues, esencial al pensamiento cartesiano; sólo por ella tendrán sentido la subjetividad y el mundo intersubjetivo. Descartes es salvado del enclaustramiento solipsista por el milagro divino, es decir, accede a la trascendencia por la vía teológica.

$\mathrm{Y}$ ahora podemos ver que si Descartes descubre pero no desarrolla el motivo trascendental, es por la función que desempeña en su metafísica la divinidad. La autointerpretación cartesiana de la conciencia es "falsa", mucho más como consecuencia de su teología que de su psicologismo. Descartes no desarrolla el motivo trascendental porque al recurrir a Dios excluye la posibilidad de concebir la conciencia como un absoluto. El ego cartesiano no es el fundador del ser por la simple razón de su dependencia frente a Dios. ${ }^{14}$ En Descartes hay el encuentro del absoluto naciente del ego moderno con el absoluto declinante del Dios

13 Es muy significativo que Descartes haya descubierto de nuevo el argumento ontológico para resolver el problema de la existencia de Dios y como consecuencia la cuestión del solipsismo. El argumento ontológico es el argumento moderno por excelencia, no obstante haber sido inventado por San Anselmo en la Edad Media. En el mundo antiguo, casi resulta inconcebible. Al rechazarlo, Santo Tomás da prueba de una gran visión; no asł Kant, que también lo rechaza.

14 El problema de la certidumbre absoluta es para Descartes un problema filosófico y también teológico. Hace notar muy bien Robinson que en el siglo xVI la teologia había dado a los espíritus la necesidad de certidumbre absoluta, que los filósofos, después, intentan trasponer a la ciencia. El solipsismo inicial cartesiano, implica ya la posibilidad de secularización de la evidencia. Sin embargo, la evidencia de Descartes no está exenta de "craite et tremblement"; es una evidencia que se apoya en Dios, una evidencia menesterosa. En cambio, la conciencia husserliana no está exenta de "voluntad de poder"; es una conciencia que descansa en si misma, autosuficiente, una inteligencia per se. 
de la Edad Media. La unión de estas dos nociones, pertenecientes a concepciones del mundo diferentes, es lo que hace imposible en el cartesianismo el desarrollo de la metafísica implicada en el "cogito, ergo sum": la metafísica como egologia.

La aporia del solipsismo plantea para Husserl la necesidad de demostrar la existencia del otro y, en consecuencia, la del mundo intersubjetivo. Husserl no prueba la existencia del otro demostrando previamente la existencia de Dios. La teoría de la apresentación analógica no recurre a la divinidad, no abandona la inmanencia de la conciencia. En lugar de abandonar la inmanencia y su certidumbre, Husserl hace frente al fantasma del solipsismo con una exploración más profunda de la conciencia, principio de la evidencia; cumple una nueva reducción fenomenológica para descubrir, en la intimidad trascendental del ego, otras mónadas y, fundar, así, la unidad intersubjetiva. Intenta, de esta manera, superar el solipsismo sin un previo abandono del carácter absoluto de la conciencia. Aunque es dudoso que pueda lograrlo, su teoría sobre las subjetividades extranjeras lo confirmará en la tesis de la conciencia absoluta, y, por ello, seguirá sosteniendo que: "Solamente la subjetividad trascendental posee el sentido de una existencia absoluta que no es relativa sino a sí misma, mientras que el mundo real es relativo a la subjetividad trascendental, relatividad que depende de su esencia misma..." 15 Descartes intenta superar el solipsismo para afirmar la trascendencia; Husserl, en cambio, afirma la existencia de la subjetividad extranjera, ahondando en la inmanencia. El resultado es, tal vez, que Descartes traiciona el motivo trascendental pero supera el solipsismo, en tanto que Husserl no traiciona este motivo pero no es seguro que supere el solipsismo.

7. La manera como Descartes y Husserl intentan dar una solución al problema del solipsismo está llena de sentido implícito. Descubrir este sentido permite acceder a dos momentos esenciales en el desarrollo de la conciencia moderna. Más aún, hace patente que esta conciencia no se ejerce en la nada; que el pensamiento "la más divina entre las cosas que parecen divinas", no excluye la voluntad de dominación.

Recuérdese el programa de Descartes, que lo es también del pensamiento clásico: "Devenir maîtres et possesseurs de la nature", "possessorem et dominum mundi". El mundo "está ahi" para ser dominado, "subjicete eam". Y la dominación se ha de realizar a través de la cogitatio, es decir, de la idea seguida necesariamente de acción. Entonces, el problema del solipsismo es el problema del acceso al mundo para

15 E. Husserl, Nachwort zu meinen Ideen etc. Jahrbuch für Philosophie etc, Halle, 1930 , p. 562. 
poder dominarlo: "yo soy mi mundo" y, como complemento, "el otro es la nada". ${ }^{16}$

“¿Cómo podría el hombre cartesiano dominar el mundo sin tener acceso a él? ¿Cómo podría tener acceso al mundo sin poder transformar el pensamiento en acción? Responden las palabras de Hugo de San Victor: "Si enim omnia Deus fecit propter homine, causa omnio homo est". El hombre cartesiano, el hombre del argumento ontológico, con el poder mágico de cambiar el pensamiento en ser: cogito, ergo sum. La inteligencia, milagro antes que magia y técnica.

8. La tesis principal del neocartesianismo husserliano afirma que "el ser deriva de la conciencia": "Solamente la subjetividad trascendental posee el sentido de una existencia absoluta que no es relativa sino a sí misma, mientras que el mundo real es relativo a la subjetividad trascendental, relatividad que depende de su esencia misma..." 17 También la existencia de Dios es relativa y por tanto reductible a la conciencia trascendental. La fenomenología quiere ser un saber absoluto y no un saber de lo absoluto. Una vez que se ha establecido el carácter absoluto de la conciencia todo otro absoluto queda excluido: el ego es creador del mundo como la divinidad; su poder constituyente lo identifica con la divinidad. ${ }^{18}$

Debemos concluir: el argumento husserliano que sirve para intentar la demostración de la existencia del otro (la apresentación analógica), al mismo tiempo que demuestra la existencia de la subjetividad extranjera demuestra la existencia de Dios, porque no es posible acceder al otro sin al mismo tiempo divinizar la conciencia. El sujeto trascendental, que constituye el ser del otro, ejerce al mismo tiempo el poder constituyente de Dios. Es así como el neocartesianismo de la fenomenología concluye en un panenteismo ateo, en un panenteismo sin Dios trascendente, en un panenteismo inmanentista..$^{19}$

Al "pienso, luego soy" de Descartes le es implícito el "principio de constitución" y este principio es la base de una metafísica y de una

$16 \mathrm{~S}$. de Beauvoir afirma que así como Descartes funda la filosofía moderna, Sade funda la ética moderna. Sade acepta las doctrinas sensualistas propuestas por su siglo, que encierran al sujeto en la inmanencia y niegan la realidad del otro. Entiende que el hombre, "amo y señor la naturaleza", tiene el derecho de "cambiar, mutilar y destruir todos los seres, como bien le plazca". En Sade se haria explícito el lado negativo en la conciencia moderna, a la que habra que entender no sólo como poder de construcción sino también como poder de destrucción. Véase S. de Beauvoir, Les écrivains célèbres, Paris, T. II, p. 226.

17 E. Husserl, Nachwort zu meinen Ideen etc...

18 O. Brúndler señala la identidad de la conciencia fenomenológica con la conciencia divina (Elementos para una filosofia de la religión, Revista de Occidente, Madrid, 1921.) En el mismo sentido, L. Chestov, Le pouvoir des clefs, París, 1928.

19 Véase, A. Caso, La filosofia de Husserl, México, 1934; M. Cabrera, Bases para una fundamentación de la sociologia; P. Ricoeur, Husserl, Evanston, 1967. 
filosofía de la historia en las cuales la afirmación de la conciencia conduce, por igual, al ser y al no ser. Lo mismo puede el hombre cartesiano, "dueño y señor del mundo", dar nacimiento a los seres, que "cambiarlos, mutilarlos y destruirlos": el ego es el fundamento de todo ser y de todo no-ser.

La metafísica que deriva el ser del pensamiento ha sido definitivamente formulada: es la egologia fenomenológica. En cambio, no ha sido formulada la metafisica que deriva el no-ser del pensamiento. Ello se debe a que esta última constituye el sentido verdaderamente oculto de la conciencia moderna, de su riqueza, de su inteligencia y de su moral. Sólo si se saca a la luz este sentido se podrá superar el solipsismo y acceder a una conciencia verdaderamente universal. 